\title{
PERFORMANCE OF RECTANGULAR PIN-FIN HEAT SINK SUBJECT TO AN IMPINGING AIR FLOW
}

\author{
Adil Abbas Mohammed ${ }^{1,}$, Saad Abdulwahab Razuqi ${ }^{2}$
}

\begin{abstract}
The heat sink is used to enhance heat rejection from heated surface to air. The seize and the geometry of the heat sink with the shape of the extended surfaces have a great influence on the heat transfer coefficient. The first step to get the optimal design is to predict the heat transfer by conduction in solid walls of heat sink and then by convection between the solid and air flow. The purpose of the present study is to predict the effectiveness of closely spaced parallel rectangular fin array arrangement. The electronic processor was represented by the copper heat sink base with thermal conductivity of $401 \mathrm{~W} / \mathrm{m} . \mathrm{K}$. The 72 fins with the geometry above mentioned were exposed to heat transfer with conduction and convection along all the boundaries except the bottom from which heat flow toward air flow domain. Mesh generation at a specific cells, number of element and number of nodes were taken under temperature difference validation. The experiments were done under impinging air flow rate with Reynolds number ranged between 4000-16000. The flow was turbulent so the $\mathrm{k}-\varepsilon$ turbulence model needed to simulate mean flow characteristics. Constant heat fluxes boundary conditions were proposed with range between $10000-70000 \mathrm{~kW} / \mathrm{m}^{2}$. The Results of temperature contour lines depicted a heat trend from the hot base through the extended surfaces to the fin tips. The fins were aligned in the core of heat sink showed higher temperature gradient compared with the fins existed in lines surrounded the core. The thermal resistance decreased as the Reynolds number increased and the Nusselt number increased as the Reynolds number increased and also when the heat flux increased. The Reynolds number depicted increasing as the Nusselt number increased and so the heat rejected from the heat sink base increased. There is a good agreement between the experimental and simulating results at error percentage not exceed $2 \%$.
\end{abstract}

\section{Keywords: Forced Convection, Heat Transfer, Heat Sink, Rectangular Fins, Heat Flux, Numerical Analysis}

\section{INTRODUCTION}

Electronic components have become one of the most wide research areas since the first application with a wide variety of electric power control and heat transfer. The electronic components convert electrical power, so the best thermal management led to efficient performance and boosted the optimization studies. These components always generate unwanted heat during operation and organized in a compact and powerful assemblies, so they tend to be in a small scale. The small size of the cooling system need to use the air flow at moderate velocities as a cooling fluid. As the direct proportion relation between the dissipated heat powers generated during the conversion by the system and to avoid potential system faults. This because of improper thermal management in such systems may exist through the thermal passages of electronic components leading to a system failure. So for these reasons, hard efforts must be taken to find and develop an effective method to manage the heat generated and to increase system reliability by appropriate cooling requirements. For electronic components the continuous heat transfer from substrate first axially by heat conduction through the fins toward the upstream direction. Practically with electronic systems, for the thermal loading heat transfer enhancement, heat sink with extended heat transfer surfaces are often used with a typical fins arrangement and air flow direction through the channels. The characteristics of impingement cooling on plate fin heat sinks like inlet widths with various airflow velocities and the geometry seize including fin spacing and fin heights influence on thermal performance in rectangular channels [1]. The impingement flow develop pressure drop it can be measured experimentally. Air flow configurations and fin geometries have considered rectangular fins by [2] with impinging air flow on the fin assembly at the central region and exited outwards at right angle in both directions through the rectangular channels formed by the cooling fins. The effect of air flow entrance is obvious on the coefficient of heat transfer and fin efficiency. Engineers need to select the high efficient heat sink with the best performance among a wide range sorts of heat sinks working under impinging jet from the comparison of thermal resistances of the optimized pin

This paper was recommended for publication in revised form by Regional Editor Hatice Mercan

${ }^{1}$ Department of Mechanical Engineering, University of Mustansiriyah, Baghdad, Iraq

2 Department of Mechanical Engineering, University of Mustansiriyah, Baghdad, Iraq

*E-mail address: adilabbas@uomustansiriyah.edu.iq, Saad_abd60@yahoo.com

Orcid id: 0000-0002-2083-928X, 0000-0002-1530-0108

Manuscript Received 05 March 2019, Accepted 11 Jul 2019 
fin heat sinks. A contour map may depicts the ratio of the thermal resistances of the pin-fin heat sinks as a function of dimensionless pumping power and dimensionless length. The contour map indicates that optimized heat sinks possess lower thermal resistances than the optimized one when the dimensionless output refers to the lower values for the pumping power, and for the other dimensionless results of the heat sink length indicates large values. On the contrast the heat sinks possess higher thermal resistance when the pumping power dimensionless value is small and when the length of heat sinks dimensionless value is large. This mean that the optimized heat sinks have smaller thermal resistances [3]. The thermal management in electronic system is vital and must be reliable and efficient by taking account minimizing the weight and volume of the system, so space and weight must be at a premium [4]. The optimum design variables can be estimated numerically. This was examined by [5] for a three-dimensional heat sink module design problem. They aimed to minimize the maximum temperature in the fin array and to determine the best shape of heat sink. Their heat sink module design problem was firstly justified on the optimum fin height which became higher and the optimum fin thickness became thinner than the original fin array also the heat sink base thickness was increased. With this design the maximum temperature can be decreased. The effect of the geometry dimensions, the fin's height, fin's width and the base plate thickness of the heat sink that subjected to impingement air cooling were numerically investigated by [6]. The increase in fin width and fin high will cause to increase the heat transfer also the personal computer chassis design displayed another possible choice. The effect of the distance from the nozzle-to-heat sink, the thermal conductivity and the fin number on the thermal resistance are investigated by [7]. The practical applications need to use different values of the velocity for the working fluid, it clearly proved that when the Reynolds number increased the thermal resistance decreased, also the fin height can reduce the thermal resistance. The thermal performance simulation for various arrangements types of pin fin heat sink using COMSOL multiphysics software was carried out by [8]. The wellknown arrangements of pin fin which are inline and staggered have been compared with the proposed random arrangement that presented best thermal performance and reached to the optimal arrangement of pin fin. The conjugate predictions of heat transfer and computational fluid dynamics were carried out by [9]. For impingement heat transfer with the walls of the fins on the target taken a surface existed in midway between the impingement jet flow and aligned in the direction of the cross flow and outflow direction of the impingement cooling air in order to minimize the pressure loss. A study of heat transfer simulation by computational analysis of heat transfer increments carried by [10] using impingement of air flow in the electronic packaging systems. To get the real results which are true and independent of grid size this can due by proposing optimum and valid grid size. An alternative ANSYS model of heat transfer with pin fins has been designed by [11] to increase heat dissipation. The design ability to cool the chassis body with the heat sink joined to the CPU is adequate to cool the whole system with rectangular pin fin heat sink. Cooling method of the high temperature heat sinks with various geometrical configurations one contain fins and the other have continuous plate fins by using high speed jet were investigated impingement by [12] for various jet velocities. Numerical simulations had been performed in ANSYS FLUENT to validate the predictions from the CFD simulations, the results depicted $25 \%$ heat transfer enhancement by employing pin-fins and the ineffectiveness of the plate fins for both continuous and interrupted. The increasing of heat transfer for various pin fin heat sinks with different inline and staggered array type with circular, elliptical and square cross sections were conducted by [13], for air flow at laminar velocities by reducing the pressure gradient and thermal resistance. The pin fins distributed into a rectangular channel heated at the surface with a constant heat flux were examined by [14]. They took into account in designing their experiments effective parameters like the pin fin array distribution, the geometry of the pin fin and the distance ratio between pin fin spacing to their hydraulic diameter. The heat transfer prediction for the effectiveness of two types of closely spaced fins studied by [15] numerically. For two types arrangement cooling by air fan away from the heatsink fixed outside on the heat sink to let the axial air flow and the other with enclosure cutout template. The enclosure cutout template more effective. The interest of the current study is highlighting on the impingement air flow effecting on rectangular pin fin geometry. The research view is to improve a simple model for prospecting the coefficient of impingement air cooling heat transfer. Experimental procedures of thermal resistance readings are accomplished on heat sink with airflow under different velocities. Motivated by aforementioned studies we formulate the problem to handle the cases with rectangular fins, copper made. As far as to our knowledge this case with this specific geometry, dimensions and the working heat transfer parameters here in after has not discussed before in the literatures. 


\section{MATHEMATICAL MODEL}

The mathematical models are simplified for characterizing the commonly engineering models released heat transfer by force convention, using the Navier-Stokes equations and energy equation.

Continuity equation

$$
\frac{\partial u}{\partial x}+\frac{\partial v}{\partial y}+\frac{\partial w}{\partial z}=0
$$

Momentum Equation

The momentum equations in $\mathrm{x}, \mathrm{y}$ and $\mathrm{z}$ directions can be written as: [3]

$$
\begin{gathered}
\rho u \frac{\partial u}{\partial x}+\rho v \frac{\partial u}{\partial y}+\rho w \frac{\partial u}{\partial z}=-\frac{\partial p}{\partial x}+\mu\left[\frac{\partial^{2} u}{\partial x^{2}}+\frac{\partial^{2} u}{\partial y^{2}}+\frac{\partial^{2} u}{\partial z^{2}}\right] \\
\rho u \frac{\partial v}{\partial x}+\rho v \frac{\partial v}{\partial y}+\rho w \frac{\partial v}{\partial z}=-\frac{\partial p}{\partial y}+\mu\left[\frac{\partial^{2} v}{\partial x^{2}}+\frac{\partial^{2} v}{\partial y^{2}}+\frac{\partial^{2} v}{\partial z^{2}}\right] \\
\rho u \frac{\partial w}{\partial x}+\rho v \frac{\partial w}{\partial y}+\rho w \frac{\partial w}{\partial z}=-\frac{\partial p}{\partial z}+\mu\left[\frac{\partial^{2} w}{\partial x^{2}}+\frac{\partial^{2} w}{\partial y^{2}}+\frac{\partial^{2} w}{\partial z^{2}}\right]-\rho g_{z}
\end{gathered}
$$

\section{Energy Equation}

The energy equations for fluid can be written as: [5]

$$
\rho C_{p}\left(u \frac{\partial T}{\partial x}+v \frac{\partial T}{\partial y}+w \frac{\partial T}{\partial z}\right)=k_{f}\left[\frac{\partial^{2} T}{\partial x^{2}}+\frac{\partial^{2} T}{\partial y^{2}}+\frac{\partial^{2} T}{\partial z^{2}}\right]
$$

Heat Transfer Coefficient

For calculating the coefficient of heat transfer and Nusselt number: [4]

$$
\begin{gathered}
q_{w}^{\prime \prime}=-k \frac{d T}{d y} \\
Q=q_{w}^{\prime \prime} A \\
Q=h A\left(T_{w}-T_{\infty}\right) \\
h=\frac{Q}{A\left(T_{w}-T_{\infty}\right)} \\
N u=\frac{h l}{k} \\
\mathrm{DT}=\mathrm{T}_{\mathrm{h}}-\mathrm{T}_{1}
\end{gathered}
$$

where $\mathrm{T}_{\mathrm{h}}$ is the surface high temperature ${ }^{\circ} \mathrm{C}$ and $\mathrm{T}_{1}$ is the surface low temperature ${ }^{\circ} \mathrm{C}$.

$$
\mathrm{Rt}=\mathrm{DT} / \mathrm{Q}
$$

Reynolds Number

The air velocity was measured by anemometer. To calculate Reynolds number the general Equation

can be used. [1]

$$
R e=\frac{\rho V d}{\mu}
$$

where (d) the air flow diameter $0.025 \mathrm{~m}$.

\section{Problem Geometry Specification}

Heat sinks are well known used in electronic applications. They consist of high conductance materials such as copper fabricated array of fins arranged in a parallel manner as shown in Figure 1. These fins are attached to a common base. The geometry design of the heat sink and all the dimensions were suggested after surveying many open literatures. The dimensions are assumed as follows:-

At the beginning a solid copper art with dimensions $(0.5 \times 0.05 \times 0.065) \mathrm{m}$. The design was prepared by a SolidWorks program and the software file was transferred to the CNC machine. The length was chosen $0.065 \mathrm{~m}$, the base cross sectional area was $0.025 \mathrm{~m}^{2}$ and the $0.04 \mathrm{~m}$ length was used to machine 72 rectangular extended 
surfaces. The design was done in a SOLIDWORKS16 design software, so that we can import this model easily in ANSYS.15.0.7

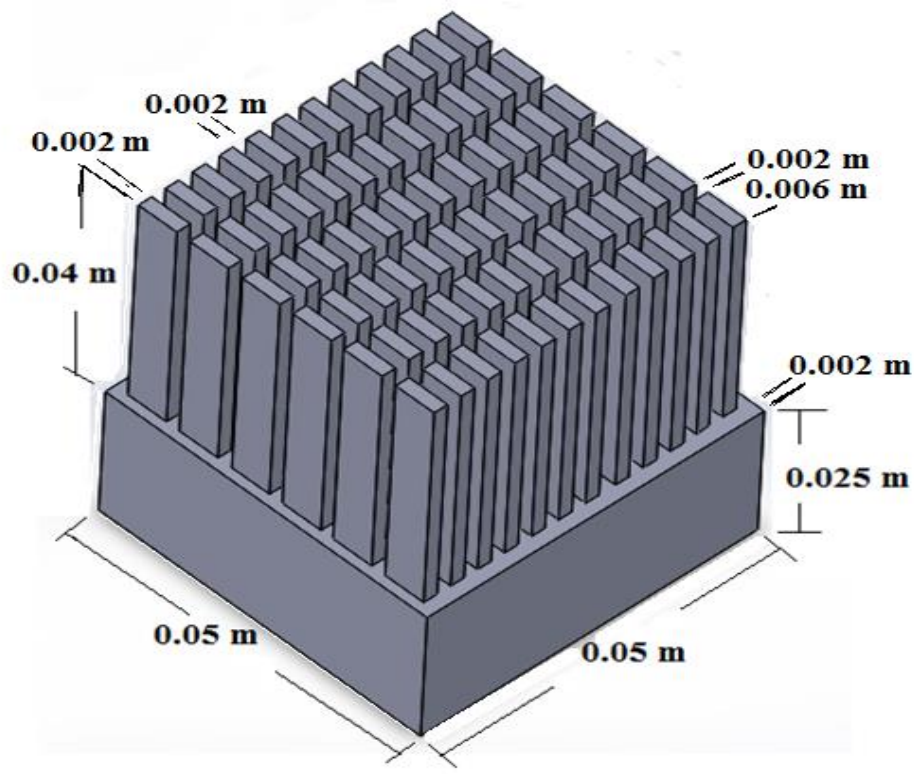

Figure 1. Heat sink with a rectangular pin fins

\section{NUMERICAL PREDICTION}

A predictive investigation of three-dimensional (3D), incompressible, steady state and turbulent forced convection heat transfer has been carried on a rectangular pin fin array using a package software of ANSYS-FLUENT (version15.0.7). The heat transfer performance was simulated on the flow domain shown in Figure 2 under impinging air flow with $0.025 \mathrm{~m}$ diameter out flow from electrical blower.

The pin fin array contained 72 fins spaced uniformly at $0.002 \mathrm{~m}$ apart. The heat sink test section was assumed to be made of copper with thermal conductivity of $401 \mathrm{~W} / \mathrm{m} \mathrm{K}$. The base surrounding faces were treated as adiabatic except the heating surface was assumed under constant heat flux. The Reynolds number of the air flow were taken at a range 3000-16000 at ambient temperature $300 \mathrm{~K}$. The outlet pressure was considered at atmospheric conditions. A constant heat fluxes were taken under the heat sink at a range from (10000-70000) $\mathrm{W} / \mathrm{m}^{2}$. Turbulent flow model was chosen to closely relate at the thermal performance of the heat dissipated from pin fin arrays. Physical constant properties were nearly assumed.

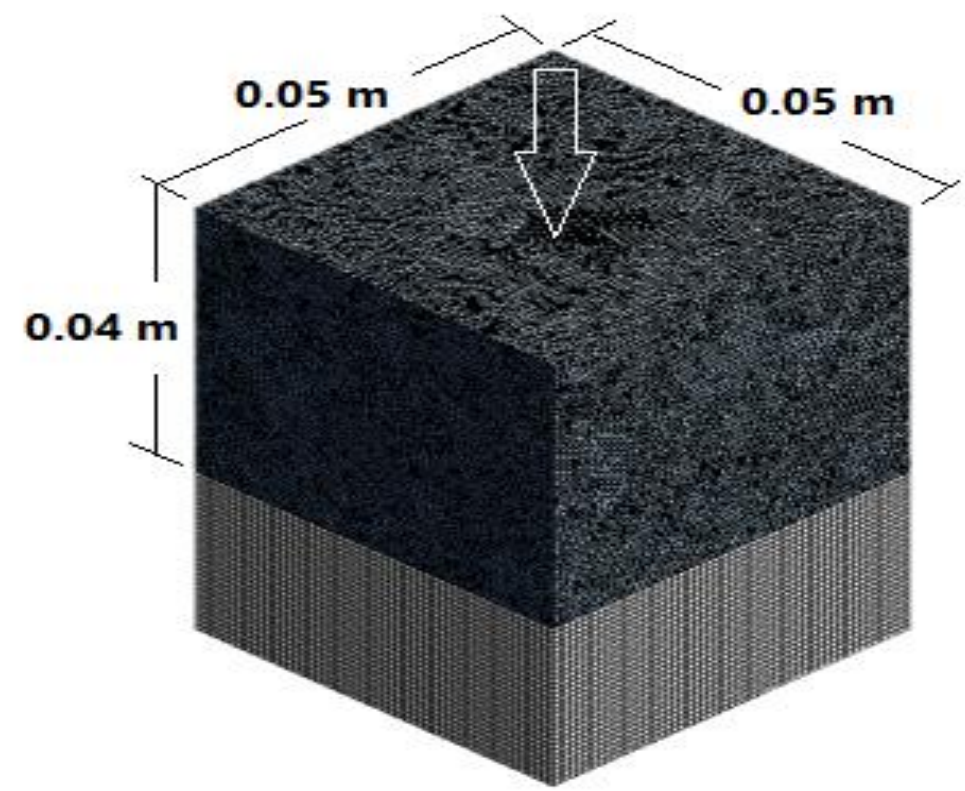

Figure 2. Air flow domain 


\section{Cfd Simulation Approach}

The simulation procedure by the ANSYS FLUENT 15.0.7 CFD code was started with pre-processing after the computational mesh which generated using mixed elements with the number of elements 1309364 and nodes 489921 Figure 3, mesh validation is clear in the Table 1.

Table 1. The validation of mesh generation

\begin{tabular}{|l|l|l|l|l|l|}
\hline & Number of Nodes & $\begin{array}{l}\text { Number of } \\
\text { Elements }\end{array}$ & $\begin{array}{l}\text { Temperature } \\
\text { Difference } \mathrm{T}_{\mathrm{h}}(\mathrm{K})\end{array}$ & $\mathrm{T}_{1}(\mathrm{~K})$ & $\mathrm{DT}\left({ }^{\circ} \mathrm{C}\right)$ \\
\hline 1 & 587277 & 1648343 & 315.4 & 312.5 & 2.9 \\
\hline 2 & 516025 & 516025 & 315.6 & 312.6 & 3 \\
\hline 3 & 489921 & 1309364 & 315.6 & 312.6 & 3 \\
\hline 4 & 357483 & 1032771 & 315.4 & 312.5 & 2.9 \\
\hline 5 & 339065 & 921439 & 315.6 & 312.7 & 2.9 \\
\hline 6 & 249764 & 651472 & 315.9 & 313.3 & 2.6 \\
\hline
\end{tabular}

A SIMPLE algorithm was used with a first order upwind discretization scheme. The coarse mesh was found to be proper for the present geometry. The flow field and heat transfer were determined by iteratively solving for the set of governing continuity, momentum and energy equations. The k- $\varepsilon$ model with the two transport equations was selected to represent the turbulent flow. The under-relaxation factors were set to stabilize the calculation process and the solution convergence at the proper time. The normalized residuals were set for velocity components at $10^{-6}$ and for energy equation at $10^{-7}$, which proved to be sufficient [16].
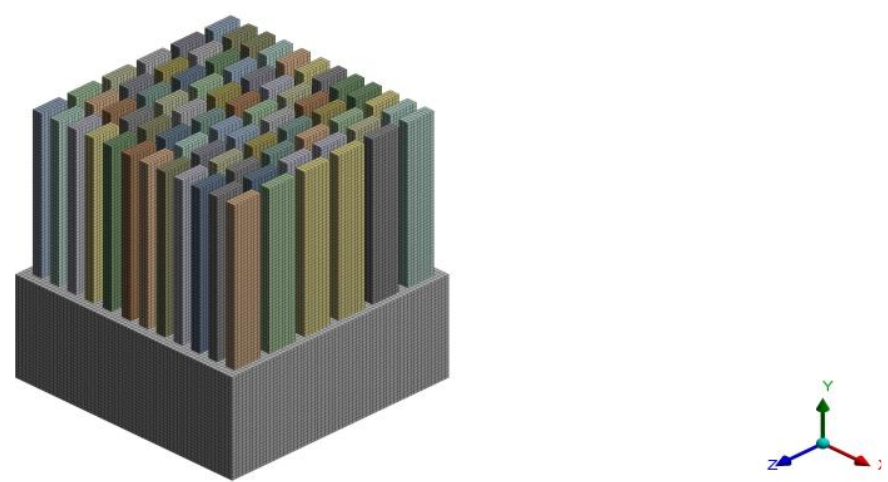

Figure 3. Mesh generation

\section{EXPERIMENTAL WORKS}

To accomplish the experimental works, a rig must be built. The main part is the test section, it was made from copper and designed with the aid of a Solid works program version 16. The outlet design was sent to CNC machine, then the final work referring to the design was machined as shown in Figure 4.
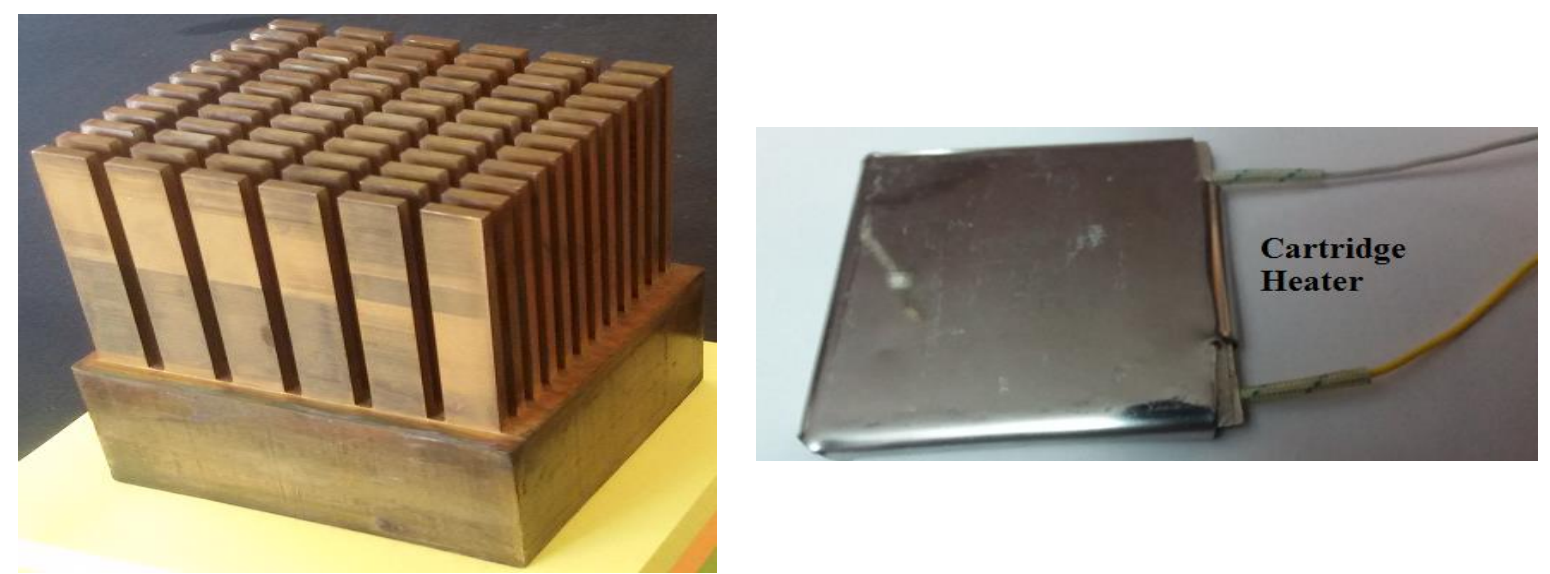

Figure 4. Test section 
The rig was assembled as shown in Figure 5, it consists from a wind duct supplied with inlet air flow by electrical blower. The constant heat flux at the test section base which simulate the heat generated by electronic component was gotten by a 750 Watt cartridge heater and setting with a regulated variable resistance. The heat was adjusted by a variable transformer variac at a range of heat varies in a range of 25-175 Watt, or heat flux $10000-70000 \mathrm{~W} / \mathrm{m}^{2}$.The temperature degrees were measured by a calibrated thermocouples type $\mathrm{K}$, and by using a temperature reader. Thermocouple type $\mathrm{K}$, with a sensitivity between 28 to $42 \mu \mathrm{V} /{ }^{\circ} \mathrm{C}$ and the thermocouple time constant which mean the time taken to reach $63.2 \%$ of the final value is modelled from 0.05 to 0.5 second.

The thermocouples were aligned in a three levels, the first one under the base above the cartridge heater to measure temperature of the heat source, the second level above the base, and the third level above the extended surfaces. The temperature readings were recorded under steady state condition. During the pre-processing steps the material must be defined. Air and copper have been chosen, so their properties were be taken in account.

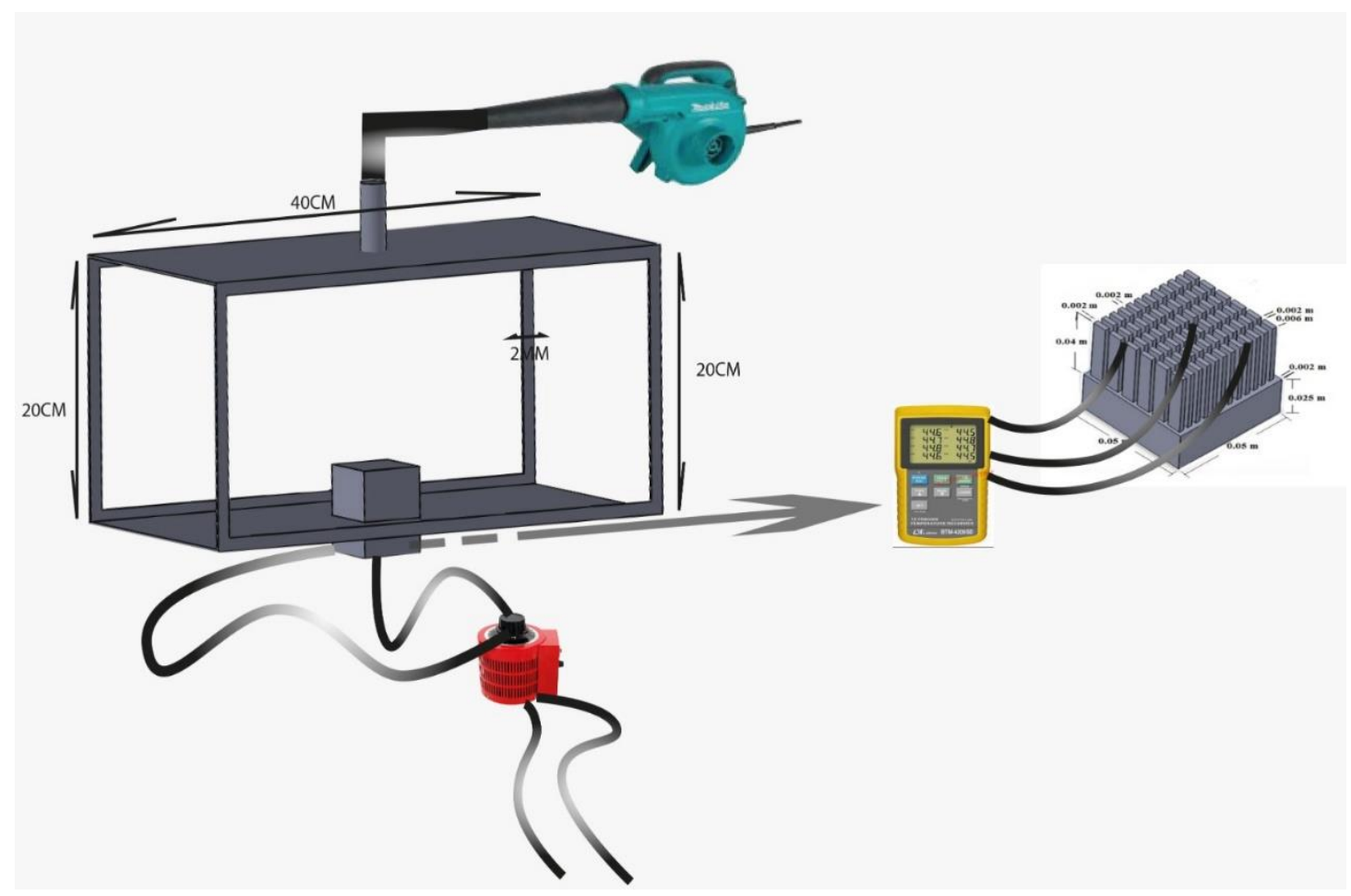

Figure 5. Test rig

\section{RESULTS AND DISCUSSION}

The main goal of the present study was to delineate the influence of utilizing rectangular pin fin heat sink. The effects of different parameters such as inlet air flow velocity, base heat flux on the temperature reduction and standard deviation of the temperature field alongside the extended surfaces were taken into account. One of the applications of heat sinks in electronic components cooling is to determine the working temperature below $100{ }^{\circ} \mathrm{C}$ [17]. The processor was represented by the copper heat sink base with a thermal conductivity of $401 \mathrm{~W} / \mathrm{m}$.K which have been extensively used as a solution [18]. The 72 fins with the geometry above mentioned were under heat transfer with conduction and convection along all the boundaries except the bottom from which heat flow toward air flow domain [19]. The experiments were done in a controlled air conditioned room at $300 \mathrm{~K}$ enters from the above side through a circular $0.025 \mathrm{~m}$ diameter duct and impinging from a distance $16 \mathrm{~cm}$ on the above part of the extended surfaces. This distance is enough to distribute the inlet air on the 72 fins. Many past attempts were done to reduce the maximum working temperature and to increase the maximum heat flux in the electronic applications by varying fins geometry and fins distribution, also the fan position with the pullout air flow was taken into account. In the present study the impinging air flow was used with different inlet velocities. Referring to the temperature variation contours Figure 6, the fins showed a good temperature gradient. 

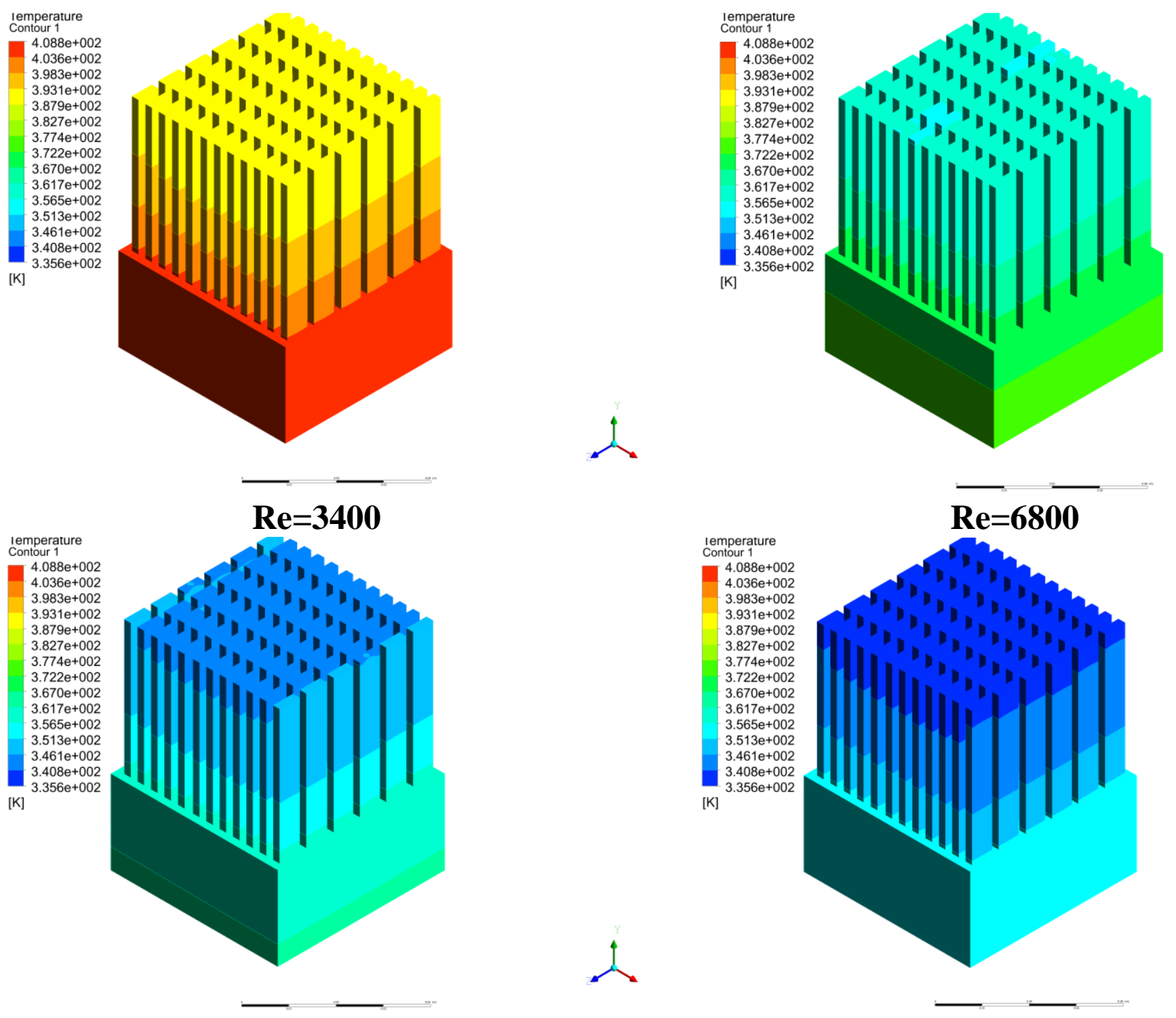

\section{$\operatorname{Re}=\mathbf{1 0 2 0 0}$}

$\operatorname{Re}=13500$
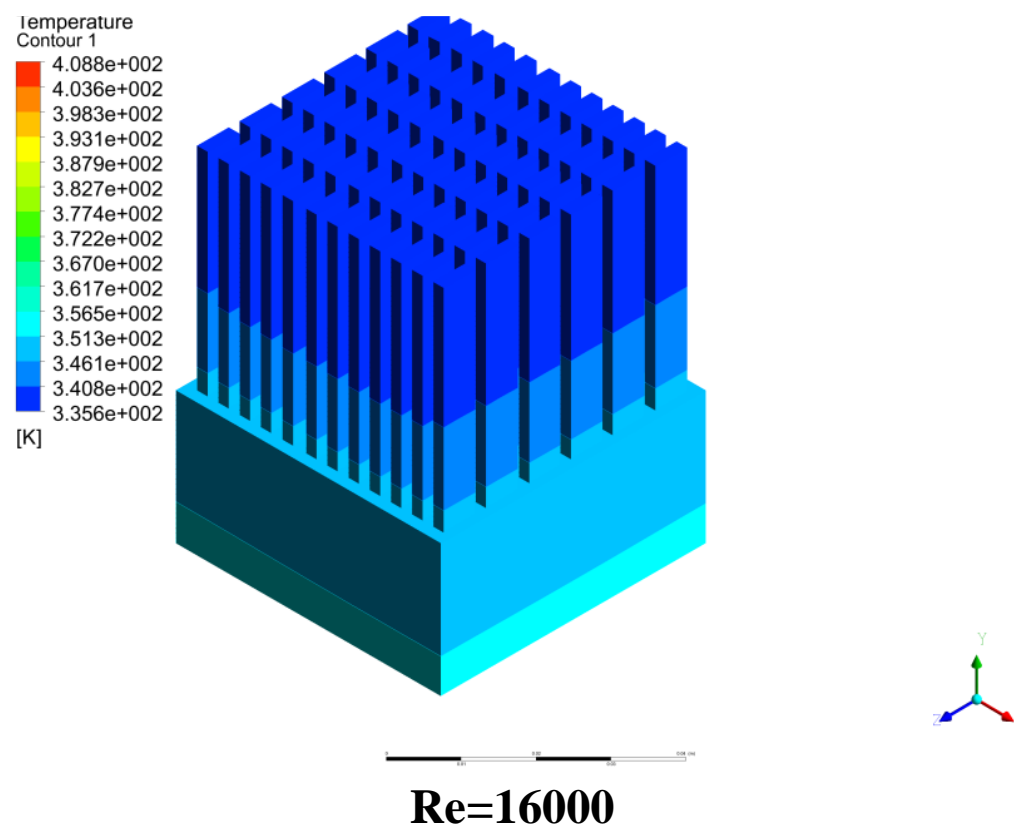

Figure 6. Temperature contour lines with heat flux $q_{w}^{\prime \prime}=70000 \frac{\mathrm{W}}{\mathrm{m}^{2}}$. 
The fins that distributed in the heat sink core showed high temperature gradient compared with the fin lines surrounded. This because their positions existed in the core of the heat sink that permitted only one air stream flow. On the other side the outside extended surfaces that distributed around the heat sink core got many air streams, one from the ambient air flow and the other from reflected air flow. Also the clearances between the fins permitted ease flow. This fact is depicted in Figure 7 by the variation of Nusselt number with Reynolds number.

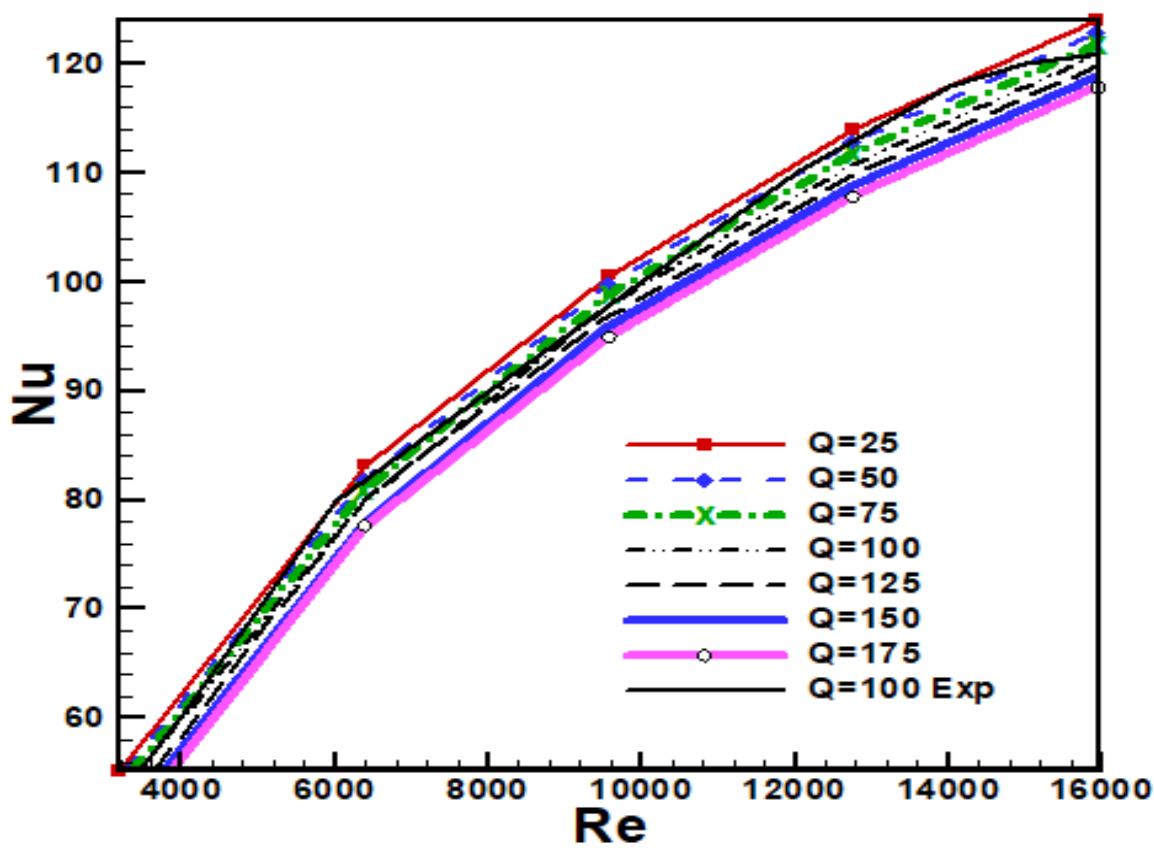

Figure 7. Variation of Nusselt number with Reynolds number

The curves trend of Nusselt number showed that the Nusselt number increases as the Reynolds number increases, and the Nusselt number decreases as the heat flux increases, this agree with [20]. The temperature difference between the heat sink base and the fins tip represent the overall heat transfer by conduction and convection. The experimental results at $(\mathrm{Q}=100 \mathrm{~W})$ with different values of Reynolds number depicted a good agreement with numerical values as shown in Figure 8 and Figure 9 depicts that the variatin of heat transfer in (Watt) with temperature difference for the rectangular fins at a specific temperature difference for numerical results. It elucidates that the heat rejected from the heated base increases as the Reynolds number increases.

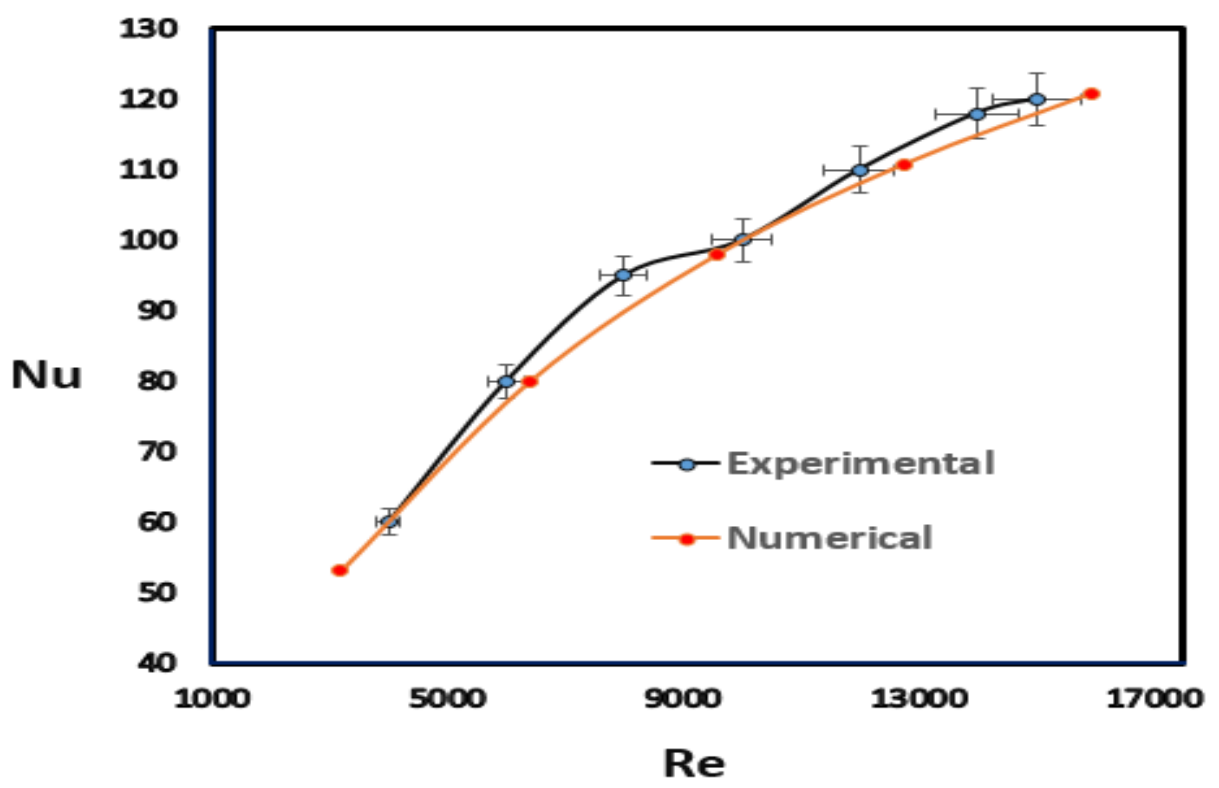

Figure 8. Nusselt number with Reynolds number for numerical and experimental results at $\mathrm{Q}=100 \mathrm{~W}$ 


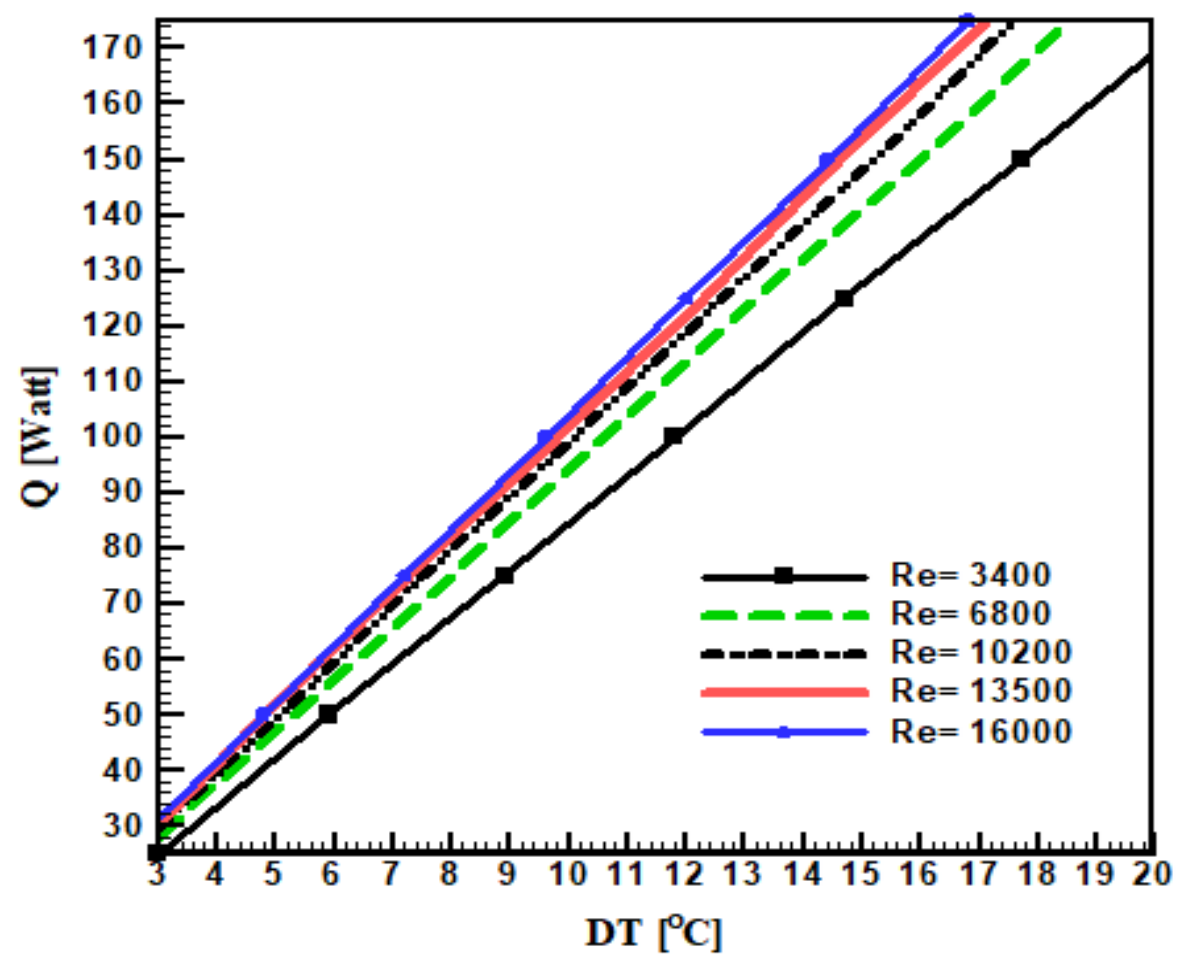

Figure 9. Variation of heat transfer with temperature difference

Figure 10 depicts that total thermal resistance in the heat sink decreases as Reynolds number increases [21]. There is a good agreement between the experimental results with the results simulation. As the increasing in Reynolds number there is a reduction in the thermal resistance. This attributes to the heat transfer coefficient enhancement by the flow turbulence which is generated by the air flow in opposite axial or transverse directions. The error deviation is clear in the error bar and it showed a value not exceed $2 \%$. The air flow is perpendicular to the tip of the fins in the blowing mode as it flows along in parallel with the surfaces of the extended surfaces, the surfaces temperatures in this mode depicted a best heat transfer performance [22].

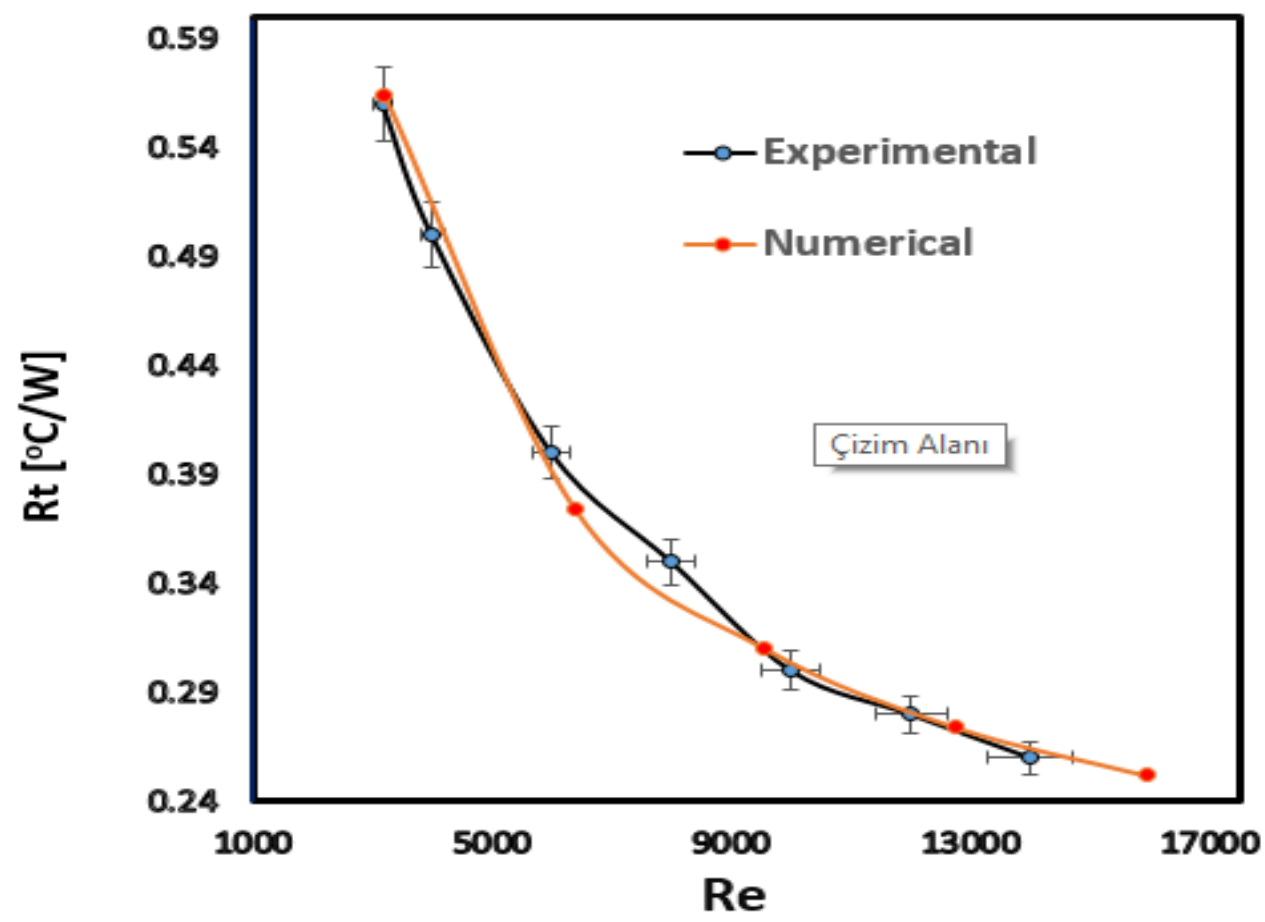

Figure 10. Variation of thermal resistance with Reynolds number 


\section{CONCLUSION}

From the investigation the following conclusions can be derived from the above results.

a- It is found that the temperature drop along the extended surfaces is consistently higher as the base heat flux increasing.

b- As the Reynolds number increases the Nusselt number increases.

c- The thermal resistance decreases as the Reynolds number increases.

d- As the Reynolds number increases the heat rejected from the heat sink base increases.

e- The Nusselt number increases as the combined increasing of Reynolds number and heat flux.

f- Temperature difference between the higher and lowest temperature degree depends on the heat flux and it is affected by Reynolds number.

g- From mesh validation, increasing mesh elements is not necessarily lead to improve the experiment results.

\section{NOMENCLATURE}

$\begin{array}{ll}\text { A } & \text { Surface area }\left[\mathrm{m}^{2}\right] \\ \text { DT } & \text { Temperature difference }\left[{ }^{\circ} \mathrm{C}\right] \\ \text { D } & \text { Diameter }[\mathrm{m}] \\ \mathrm{g} & \text { Gravity acceleration }\left[\mathrm{m} / \mathrm{s}^{2}\right] \\ \mathrm{h} & \text { Heat transfer coefficient }\left[\mathrm{W} / \mathrm{m}^{2} . \mathrm{K}\right] \\ \mathrm{k} & \text { Thermal conductivity }[\mathrm{W} / \mathrm{m} \cdot \mathrm{K}] \\ \mathrm{l} & \text { Length }[\mathrm{m}] \\ \mathrm{Nu} & \text { Nusselt number } \\ \mathrm{P} & \text { Pressure }\left[\mathrm{N} / \mathrm{m}^{2}\right] \\ q_{w}^{\prime \prime} & \text { Heat flux }\left[\mathrm{W} / \mathrm{m}^{2}\right] \\ \mathrm{Q} & \text { Heat }[\mathrm{W}] \\ \mathrm{Re} & \text { Reynolds number } \\ \mathrm{Rt} & \text { Thermal Resistance }\left[{ }^{\circ} \mathrm{C} / \mathrm{W}\right] \\ x & \text { The horizontal coordinate, }[\mathrm{m}] \\ \mathrm{T} & \text { Temperature }[\mathrm{K}] \\ \mathrm{U} & \text { The horizontal velocity component in } \mathrm{x} \text { direction, }[\mathrm{m} / \mathrm{s}] \\ \mathrm{V} & \text { The vertical velocity component in y direction, }[\mathrm{m} / \mathrm{s}] \\ \mathrm{W} & \text { The horizontal velocity component in z direction, }[\mathrm{m} / \mathrm{s}]\end{array}$

Greek symbols

$\begin{array}{ll}\mu & \text { Dynamic viscosity, }\left[\mathrm{N} . \mathrm{s} / \mathrm{m}^{2}\right] \\ \rho & \text { Density }\left[\mathrm{kg} / \mathrm{m}^{3}\right] \\ \text { Subscript } & \\ \text { W } & \text { Wall } \\ \infty & \text { The value at atmospheric condition } \\ \mathrm{F} & \text { Fluid }\end{array}$

\section{REFERENCES}

[1] Duan Z, Muzychka YS. Experimental investigation of heat transfer in impingement air cooled plate fin heat sinks. J. Electron. Packag, vol. 128, no. 4, pp. 412-418, 2006. doi: 10.1115/1.2351906.

[2] Duan Z, Mzychka YS. Impingement air cooled plate fin heat sinks. Part II-Thermal resistance model. InThe Ninth Intersociety Conference on Thermal and Thermomechanical Phenomena In Electronic Systems (IEEE Cat. No. 04CH37543) 2004 Jun 1 (Vol. 1, pp. 436-443). IEEE. doi: 10.1109/ITHERM.2004.1319207.

[3] Kim DK, Kim SJ, Bae JK. Comparison of thermal performances of plate-fin and pin-fin heat sinks subject to an impinging flow. International Journal of Heat and Mass Transfer. 2009 Jul 1;52(15-16):3510-7. doi:10.1016/j.ijheatmasstransfer.2009.02.041.

[4] D. BK, Khan NA. Experimental and CFD Analysis of Aluminum Heat Sinks for Avionics Applications. IJIRST-International J. Innov. Res. Sci. Technol., vol. 3, 2016.

[5] Huang CH, Lu JJ, Ay H. A three-dimensional heat sink module design problem with experimental verification. Int. J. Innov. Res. Sci. Technol., vol. 3, no. 2, p. 2349, 2016. 
doi:10.1016/j.ijheatmasstransfer.2010.11.044.

[6] Tien HC, Huang WD. Simulation and assessment of air impingement cooling on squared pin-fin heat sinks applied in personal computers. Journal of Marine Science and Technology. 2005 Mar 1;13(1):20-7.

[7] Li HY, Chiang MH, Chen KY. Performance analysis of pin-fin heat sinks with confined impingement cooling. IEEE transactions on components and packaging technologies. 2007 Aug 27;30(3):383-9. doi: 10.1109/TCAPT.2007.900052.

[8] Rosli R, Annuar KM, Ismail FS. Optimal pin fin heat sink arrangement for solving thermal distribution problem. J. Adv. Res. Fluid Mech. Therm. Sci. 2015;11:1-8.

[9] El-Jummah AM, Andrews GE, Staggs JE. Impingement Jet Cooling with Ribs and Pin Fin Obstacles in Co-flow Configurations: Conjugate Heat Transfer Computational Fluid Dynamic Predictions. InASME Turbo Expo 2016: Turbomachinery Technical Conference and Exposition 2016. American Society of Mechanical Engineers Digital Collection. pp. 13-17. doi.org/10.1115/GT2016-57021.

[10] Umair SM, Gulhane NP. On numerical investigation of heat transfer augmentation through pin fin heat sink by laterally impinging air jet. Procedia Engineering. 2016 Jan 1;157:89-97.

[11] Ravikumar S, Chandra PS, Harish R, Sivaji T. Experimental and Transient Thermal Analysis of Heat Sink Fin for CPU processor for better performance. InIOP Conference Series: Materials Science and Engineering 2017 May 1 (Vol. 197, No. 1, p. 012085). IOP Publishing. doi:10.1088/1757899X/197/1/012085.

[12] Vedpathak S. Optimization of Impingement Cooled Heat Sink using Experimental and CFD Simulation Methods. Int. J. Res. Appl. Sci. Eng. Technol., vol. 6, no. 7, pp. 122-131, Jul. 2018. doi:10.22214/ijraset.2018.7018.

[13] D. Sharath, Sathyanarayana, and H. . Puneeth, "Heat Transfer Numerical Simulation and Optimization of a Heat Sinks," in IOP Conference Series: Materials Science and Engineering, 2018, vol. 376, p. 012005. doi:10.1088/1757-899X/376/1/012005.

[14] Caliskan S, Dogan A, Kotcioglu I. Experimental investigation of heat transfer from different pin fin in a rectangular channel. Exp. Heat Transf., pp. 1-17, Oct. 2018. doi.org/10.1080/08916152.2018.1526228

[15] Mohammed AA, Razuqi SA, Forced Convection Heat Transfer Of Axial Air Flow With Heatsink On Uniform Heat Flux. Heat Eng. Sustain. Dev., vol. 22, no. 2, pp. 10-21, 2018.

[16] Dange M, Deshmukh MS. Experimental Analysis of Cylindrical Staggered Pin Fin Heat Sink for Force Convective Heat Transfer Variation and its Enhancement. Int. J. Latest Eng. Res. Appl., vol. 2, no. 8, pp. 128-133, 2017.

[17] Tuckerman DB, Pease RFW. High-performance heat sinking for VLSI. IEEE Electron Device Lett., vol. 2, no. 5, pp. 126-129, 1981. doi: 10.1109/EDL.1981.25367.

[18] Karatekin C, Kökkaya O. Comparative analysis of different cooling fin types for countering LED luminaires' heat problems. journals.tubitak.gov.tr.

[19] Alkasassbeh M, Omar Z, Mebarek-Oudina F, Raza J, Chamkha A. Heat transfer study of convective fin with temperature-dependent internal heat generation by hybrid block method. Heat Transfer-Asian Research. 2019 Jun;48(4):1225-44. doi.org/10.1002/htj.21428.

[20] Muthukumarn R, Rathnasamy R, Karthikeyan R. Experimental Study of Performance of Pin Fin Heat Sink under Forced Convection. Int. J. Mech. Inf. Technol., vol. 04, no. 10, pp. 1791-1796, 2016. doi:10.18535/ijmeit/v4i10.02.

[21] Kumar V, Rao B, Farooq Sk. Thermal Analysis of Rectangular and Tapered Pin fins heat sink using Icepak International Conference on Allied Technologies in Electrical \& Communication systems, 2016.

[22] Abuşka M, Şevik S, Altıntaş V. The Effect Of Blowing Direction On Heat Sink Performance By Thermal Imaging. Journal of Thermal Engineering, Yildiz Technical University Press, Istanbul, Turkey, Vol. 4, No. 6, pp. 2471-2480, October, 2018. doi: 10.18186/thermal.465695. 